Differential Toll like receptor expression in cystic fibrosis patients' airways during rhinovirus infection

Toll like receptors in cystic fibrosis

Carolina Scagnolari ${ }^{1}$, Camilla Bitossi ${ }^{1}$, Federica Frasca ${ }^{1}$, Agnese Viscido ${ }^{1}$, Gabriele Brazzini ${ }^{1}$, Maria Trancassini $^{2}$, Valeria Pietropaolo ${ }^{2}$, Fabio Midulla $^{3}$, Giuseppe Cimino ${ }^{4}$, Paolo Palange ${ }^{2}$, Alessandra Pierangeli ${ }^{1}$, Guido Antonelli ${ }^{1}$.

1) Virology Laboratory, Department of Molecular Medicine, Affiliated to Pasteur Institute Italy, Cenci Bolognetti Foundation, Sapienza University, Viale di Porta Tiburtina, 28, 00185, Rome, Italy.

2) Department of Public Health and Infectious Diseases, Sapienza University, Piazzale Aldo Moro, 5, 00185 Rome, Italy.

3) Department of Pediatrics, Policlinico Umberto I University Hospital, Sapienza University, Viale del Policlinico, 155, 00161 Roma RM Rome, Italy.

4) Lazio Reference Center for Cystic Fibrosis, Policlinico Umberto I University Hospital, Sapienza University, Viale del Policlinico, 155, 00161 Roma RM Rome, Italy.

Corresponding Author

Carolina Scagnolari

Associate Professor of Virology

Pasteur Institute-Cenci Bolognetti Foundation,

Department of Molecular Medicine, Laboratory of Virology

Sapienza University of Rome

Viale di Porta Tiburtina ${ }^{\circ} 28,00185$, Rome (Tel: +39 06 44741220)

carolina.scagnolari@uniroma1.it

\title{
Conflicts of interests:
}

The authors declare that they have no conflicts of interests. 


\section{Highlights}

- $\mathrm{HRV}$ is frequently found in the respiratory tract of CF patients

- HRV can be associated to pulmonary exacerbations in CF patients

- HRV load did not vary according to CF patients age

- HRV infection affects the expression of TLRs in CF patients

- $\quad$ TLR2 and TLR4 levels are increased in HRV positive CF patients

- TLRs expression changed according to the specific HRV-bacteria species interaction 


\begin{abstract}
:
Objectives: Since an inappropriate and sustained activation of TLRs may contribute to a chronic inflammatory response resulting in detrimental effects in cystic fibrosis $(\mathrm{CF})$ patients, we sought to examine whether HRV infection might alter the respiratory expression of TLRs according to the microbiological status of CF patients.

Methods: Respiratory samples were collected from the respiratory tract of CF patients $(n=294)$ over a period of 12 months. In addition to the usual microbiological investigation, HRV-RNA detection and typing were performed by RT-PCR and sequencing. HRV viral load and TLRs levels were measured by RT-Real Time PCR.

Results: HRV-RNA was detected in 80 out of 515 respiratory samples (15.5\%) with a similar rate in all age groups (0-10 years, 11-24 years, $\geq 25$ years). Patients infected with different HRV A, B and C species exhibited higher levels of TLR2, TLR4 and TLR8 as compared to HRV negative patients. Moreover, the expression level of TLR2, TLR4 and TLR8 correlated with high level of HRV viral load. HRV positive patients co-colonized by Staphylococcus aureus or Pseudomonas aeruginosa showed also enhanced amounts of TLR2 and TLR2/4-mRNAs expression respectively. In the case of presence of both bacteria, TLR2, TLR4, TLR8 and TLR9 levels are elevated in positive HRV patients. Conclusions: TLRs, especially TLR2 and TLR4, increased in HRV positive CF individuals and varies according to the presence of $S$. aureus, $P$. aeruginosa and both bacteria.
\end{abstract}

Keywords: cystic fibrosis, rhinovirus, toll like receptors, viral load, virus-bacteria interaction 


\section{Introduction}

Chronic lung disease remains the primary cause of mortality in cystic fibrosis (CF). The classic bacteria implicated in CF pathology, Pseudomonas aeruginosa and Staphylococcus aureus, by colonizing airway epithelial, activate innate response through toll-like receptors (TLRs) [1, 2]. All TLRs (1-10), and their adaptor molecule, MyD88, are expressed and functional in CF airway epithelia; however, most of the related studies are derived from in vitro/ex vivo investigations or were obtained from mouse model $[3,4]$. Stimulation of airway epithelial cells with $P$. aeruginosa enhances the expression of TLR2 and TLR5 on the epithelial cell surface $[5,6,7]$ and TLR2 may be increased in $\mathrm{CF}$ as compared with normal epithelial cells [2]. Moreover, an altered TLR4 expression has been found in CF airways cells $[8,9]$, together with a persistent expression of this recognition receptor due to the apparent inability of CF cells to target TLR4 toward the lysosome for degradation [10]. Multiple bacterial exoproducts, such as flagellin and lipoproteins, were also shown to induce through TLRs a strong production of the neutrophil chemoattractant IL-8, leading to an increased inflammatory response $[11,12]$. Also, it is well established that one of the most important airway defence mechanism against respiratory viral infections is the activation of TLRs response. However, the role of respiratory viruses on the development of airway disease in CF patients is poorly understood [13, 14]. Among respiratory viruses, human rhinovirus (HRV) is likely the most commonly detected virus in $\mathrm{CF}$, showing a high prevalence in upper and lower respiratory samples of children and adults suffering from CF $[15,16]$. HRV infection in CF disease was associated to greater inflammation [17], worse lung function, reduced quality of life, hospitalization and required more days of antibiotic treatment upon concomitant bacterial infection [18, 19]. Of note, the viral capsid of HRV can bind TLR2, while ssRNA is recognized by TLR7 and 8 [20, 21]; TLR2 expression appeared also to be required for early inflammatory responses induced by HRV [22]. Moreover, an increased expression of TLR9 has been also recorded in sinonasal epithelial cells of CF patients frequently suffer from chronic rhinosinus [23]. Indeed, in the setting of polymicrobial colonization or infection of the respiratory tract, how the different bacterial and viral stimuli affect airway TLRs response in CF 
disease remains largely unknown [24]. Undoubtedly, identification of the specific TLRs that can be targeted to dampen an overexuberant inflammatory response in $\mathrm{CF}$ airway might be extremely interesting to better understand the pathogenesis of respiratory infections, in general and in $\mathrm{CF}$ in particular.

\section{Objectives}

Since an up-regulation of TLR might enhance proinflammatory responses in airway epithelial cells resulting in detrimental effects in CF patients [25], we sought to examine how HRV infection influences the respiratory expression of TLRs according to the microbiological status of CF patients. Thus, the main contribution of the present work is the study of the gene expression of the different TLRs, which have emerged as essential pattern recognition receptors in CF and HRV infection [26, 27], in a group of HRV infected CF patients matched with a group of HRV negative CF patients.

\section{Material and methods}

\section{Study design}

Respiratory samples were collected from the respiratory tract (oropharyngeal aspirate and sputum) of CF patients attending the Regional Reference Center for Cystic Fibrosis, Policlinico Umberto I, University of Rome "Sapienza", for routine visit during 2018 (from $1^{\text {st }}$ January to $31^{\text {st }}$ December) $(n=294)$. Most patients were routinely seen in the hospital every 3 months and a total of 515 respiratory samples were collected. In addition to the usual microbiological investigation, HRV was tested by RT-PCR in all respiratory samples. The duration of HRV positivity in CF patients was also evaluated after 12 weeks later. Then, the gene expression of TLRs was performed in 55 out of 80 HRV positive patients for whom the respiratory samples (oropharyngeal aspirate $n=37$ and sputum $\mathrm{n}=18$ ) were enough for this analysis. The above respiratory samples did not differ in respect to age of CF patients (oropharyngeal aspirate samples/age of patients: mean/DVS, 18.63/13.08; sputum samples/age of patients: mean/DVS, 19.18/13.42, p>0.05). An age, gender, genetic and 
microbiological matched group of CF patients $(n=55)$ was also selected from the same cohort of patients. The study was approved by the ethics committee of the Policlinico Umberto I Hospital, Sapienza University of Rome, and informed consent was obtained from patients suffering from CF.

\section{Specimen collection}

Respiratory samples (oropharyngeal aspirate and sputum) were collected from the respiratory tract of individuals with CF during the routine visit. All sputum samples were quality assessed after slides of the specimens had been Gram-stained and microscopically examined at 100x magnification. The sputa quality was assessed according to the criteria of Bartlett et al. [28], by determining the numbers of squamous epithelial cells and polymorphonuclear cells within the following categories: $<10,10$ 25 , or $>25$ cells per representative $(\times 100)$ low power field magnification. All samples were divided into three aliquots: one was used for traditional microbiological investigations, the second was treated for nucleic acid extraction and viral detection; the third was centrifuged at $2000 \mathrm{rpm}$ for $10 \mathrm{~min}$ and each cell pellet was resuspended in $500 \mu \mathrm{l}$ of phenol and guanidine isothiocyanate reagent (Trizol, Gibco-BRL, Green Island, NY, USA) and frozen at $-80{ }^{\circ} \mathrm{C}$ for gene expression analysis.

\section{Microbiological investigations}

Standard methods and procedures were followed for the traditional microbiological investigation: respiratory tract samples were analyzed for common and emerging microorganisms by using appropriate media (BD BBL ${ }^{\mathrm{TM}}$ Stacker Plates, Heidelberg, Germany). Matrix-assisted laser desorption/ionization time-of-flight mass spectrometry (MALDI-TOF MS) (Bruker Daltonics, Inc., Billerica, MA, USA) was used for identification where necessary. Patients with CF were recognized as chronically colonized by $P$. aeruginosa in accordance to European consensus criteria [29]. Patients with $S$. aureus were considered to have a persistent colonization if they had three or more consecutive S. aureus isolates over at least 12 months [30]. 
HRV detection and sequencing

HRV positivity was tested with PCR-based tests, as previously described [31, 32]. Prior to testing for $\mathrm{HRV}$, the random primer-directed RT reaction, each sample was subjected to PCR amplification of the invariant $\beta$-actin gene to rule out the occurrence of PCR inhibitors; if $\beta$-actin PCR was negative, specimens were re-extracted from a frozen aliquot. HRV positive samples used for TLRs analysis were also typed as HRV A, B or C species. Briefly, HRV positive samples were retrospectively amplified with primers widely used for genotyping targeting 390 bases of the 5'untranslated region (5'UTR) central portion [33]. Direct amplicon sequencing was performed with Big Dye chain terminator reactions on an ABI 3130xl instrument.

\section{TaqMan-based real-time RT-PCR technique for HRV quantification}

TaqMan-based real-time PCR technique for HRV-RNA quantification was performed on all respiratory specimens with positive RT-PCR results for HRV [34]. Prior to testing for HRV, internal noncompetitive control, the housekeeping gene $\beta$-glucuronidase (GUS), was used to rule out the occurrence of amplification inhibitors. Briefly, RNA was extracted from oropharyngeal aspirate and sputum samples that were positive for HRV using a QIAamp Viral RNA Mini Kit (Qiagen, Milan, Italy). The RNA was dissolved in RNase-free water and the HRV quantification and GUS evaluation was performed by Taqman assay after generation of cDNA using a High Capacity cDNA Archive Kit (Applied Bio-systems, Monza, Italy). The following primers and probes for 5'UTR region of HRV A, B, C genotypes [35] and GUS [36] were added to the universal PCR master mix (Roche) at 600 (HRV), 500 (GUS) and 400 (HRV), 250 (GUS) nM, respectively, in a final volume of $20 \mu 1$. The standards for HRV were obtained cloning the $203 \mathrm{bp}$ of the 5'UTR-HRV region into the pCR2.1 plasmid using a TOPO TA cloning kit (Invitrogen Corporation, San Diego, CA, USA). A linear distribution ( $\mathrm{r}=0.99)$ was obtained between $10^{1}$ and $10^{8}$ copies of HRV-DNA. Viral load values were Log transformed for analysis and data were expressed as the Log number of HRV copies per ml of respiratory specimens. All the determinations were performed in duplicate. 
TaqMan-Based Real-Time RT-PCR Assays for mRNA Expression

Quantitative real-time PCR for TLRs members (TLR2, TLR3, TLR4, TLR8, TLR9), was carried out with the LightCycler 480 instrument (Roche, Basel, Switzerland). Briefly, total RNA was extracted from respiratory samples using the RNeasy Plus Universal Tissue Mini Kit (Invitrogen, Carlsbad, CA, USA) and reverse transcribed using the High Capacity cDNA Reverse Transcription Kit (Applied Biosystems, USA), according to the manufacturer's protocol. Primers and probes for each gene were added to the Probes Master Mix (Roche, Basel, Switzerland) at 500 and $250 \mathrm{nM}$, respectively, in a final volume of $20 \mu \mathrm{L}$. The housekeeping gene $\beta$-glucuronidase/GUS was used as an internal control. Gene expression values were calculated by the comparative $\mathrm{Ct}$ method. The primers and probes targeting the following TLRs were assayed on demand and purchased from Integrated DNA Technologies (IDT, Coralville, IA, USA): TLR2 (Hs.PT.58.21312907), TLR3 (Hs.PT.58.25887499.g), TLR4 (Hs.PT.58.38700156.g), TLR5 (Hs.PT.58.25167562), TLR8 (Hs.PT.58.15.023918.g), TLR9 (Hs.PT.58.40576968).

\section{Statistical Analysis}

Data are expressed as median/range or otherwise indicated. The demographic and clinical characteristics were compared using Chi-Squared tests. HRV load between age groups was tested by Kruskal-Wallis test. Differences in the levels of TLRs members (TLR2, TLR3, TLR4, TLR8, TLR9) between HRV-infected CF patients and those negative for HRV infection were evaluated using the Mann-Whitney test. The same test was used to compare the levels of mRNA of TLRs members between $\mathrm{HRV}$-infected $\mathrm{CF}$ patients and those negative for HRV infection according to the microbiological status. Mann-Whitney test was also used to evaluate if respiratory samples differed in respect to age of CF patients. Spearman's rho coefficient was calculated to assess the correlation between HRV load, FEV1, age and TLRs levels. Comparison between TLRs expression levels in HRV positive and negative CF patients was performed by Wilcoxon Signed Rank Test. Differences 
were considered statistically significant when $\mathrm{p}<0.05$. All analyses were performed with the SPSS v.20.0 for Windows.

\section{Results}

\section{Detection of HRV-RNA in CF patients}

Demographic and clinical characteristics of CF patients examined are reported in Table 1. In particular, respiratory samples were collected from the respiratory tract of CF individuals which were subsequently divided into three age groups according to the bacteriological setting and disease evolution: the children group (0-10 years; $n=131)$, adolescents/young adults (11-24 years; $n=170)$ and the older group ( $\geq 25$ years; $n=214$ ). HRV-RNA was detected in 80 out of 515 respiratory samples $(15.5 \%)$ with a similar rate in all age groups: $23 / 131(17.5 \%)$ in the children, $33 / 170(19.4 \%)$ in the adolescent/young adults and 24/214 (11.2\%) in the older group. Moreover, the HRV viral load levels measured in HRV positive respiratory samples were comparable between the three age groups of $\mathrm{CF}$ patients analyzed (Table 1). The HRV infection prevalence in all age groups was not related to the presence of $S$. aureus and P. aeruginosa, alone or in co-colonization (Fig.1).

Since the capability of HRV to cause persistent infection of the respiratory tract in patients with CF is not well defined [37], the duration of HRV positivity in patients with CF was also evaluated. None of HRV infected patients had a prolonged infection (i.e. no patient was HRV positive in two subsequent samples taken with a frequency of 12 weeks).

\section{TLRs expression in HRV positive and negative CF patients}

We evaluated the gene expression of TLR2, TLR3, TLR4, TLR8 and TLR9 in HRV positive patients $(n=55)$ and in a second group of HRV negative CF patients $(n=55)$ matched for age, gender, CFTR genetic, microbiology and respiratory samples (HRV positive versus HRV negative, $\mathrm{p}>0.05$ for all the parameters). The identification of HRV was associated with pulmonary exacerbations in 10 out of 55 CF patients analysed. By contrast, the remaining HRV positive CF patients $(n=45)$ had self- 
limiting and mild upper respiratory symptoms. An increased expression of TLR2 and TLR4 was observed in HRV positive patients compared to those without HRV infection (Fig. 2, Panel A, C). By contrast, the expression of TLR9, TLR3 and TLR8 remained almost unchanged (TLR3 and TLR9) or slightly increased (TLR8) in HRV positive CF patients compared to the HRV negative patients (Fig. 2, Panel B, D, E). Furthermore, HRV infected patients exhibited a different TLR magnitude from HRV negative individuals (Fig. 2, Panel F); TLR4 was 7-, 5- and 14-fold increased compared to TLR3 ( $\mathrm{p}<0.001)$, TLR8 ( $\mathrm{p}<0.001)$ and TLR9 $(\mathrm{p}<0.001)$ respectively, while the differences between TLR4- and TLR2-mRNA amounts were not significant ( $\mathrm{p}=0.111$ ). By contrast, TLR4 expression levels in HRV negative individuals were 2-, 4-, 4- and 9-fold increased compared to TLR2 (p=0.002), TLR3 (p<0.001), TLR8 (p<0.001) and TLR9 (p<0.001) respectively (Fig. 2, Panel F).

Since recent studies have implicated certain species of HRV as being more pathogenic [18, 38], we also evaluated whether HRV A, B and C species were associated with different gene expression of TLRs in CF patients. HRV A was identified in 24 (43.6\%) CF patients, HRV B in 12 (21.8\%), and HRV C in 19 (34.6\%). Significant differences in transcript levels of TLR2, TLR4, and TLR8, but not TLR3 and TLR9, were observed between patients with HRV A, B and C strains as compared to those without HRV infection (Table 2).

Then, to determine whether differentially expressed TLRs could also influence HRV viral load (and viceversa), levels of TLR2, TLR3, TLR4, TLR8 and TLR9 were also examined for any significant correlation with HRV load measured in the same respiratory samples. A positive correlation between HRV-RNA levels and TLR2, TLR4 and TLR8 gene expression, but not with the other TLR analyzed, was found (Table 3).

\section{TLR expression in HRV positive and negative CF patients according to the microbiological status}

Since polymicrobial colonization are common in CF respiratory tract and may differently activate TLRs, their expression in HRV positive and HRV negative patients was then analyzed stratifying patients according to presence of $S$. aureus, of $P$. aeruginosa or both. 
In the case of $S$. aureus only the group of CF patients with an age less than 18 years $(\mathrm{n}=28$, years range: 0.58-17.76) were considered, because this bacterium is the earliest in the younger ones [39]. A different expression of TLR2 was found in HRV positive patients in the presence of S. aureus compared to those without HRV infection (Fig. 2, Panel A). Moreover, HRV positive CF patients persistently colonized by $P$. aeruginosa exhibited higher levels of TLR 2 and TLR 4 compared to those negative for HRV (Fig. 2, Panel A, C). In the case of co-colonization by both bacteria, TLR2, TLR4, TLR8 and TLR9 levels are significantly elevated in positive HRV patients (Fig. 2, Panel A, C, D, E), whose expression increase from 1.8 (TLR 8) to 4.6 (TLR2) times.

\section{Relationship between TLR expression and demographic, clinical and virological parameters}

Having observed a differential expression of some TLRs in the respiratory tract of HRV infected CF patients, we evaluated whether there was any relation between TLRs expression and demographic and clinical parameters. Results indicated that TLRs levels were not correlated to the age and to the FEV levels recorded in CF patients according to the presence or absence of HRV infection (Table 3).

\section{Discussion}

The underlying mechanisms leading to pulmonary inflammation in CF are basically unknown. Some authors proposed that it may be promoted by an exaggerated or excessively prolonged innate immune response [40, 41]. Polymicrobial communities can colonize the respiratory tract in CF lung disease and viral infections, mostly caused by $\operatorname{HRV}[42,43,44]$, may contribute to the lower airway inflammation in patients with CF [45]. However, the impact of HRV-bacteria interplay on the innate immune response, inflammation and development of airway CF disease is poorly understood. TLRs appeared to play an important role in these events [4]. Indeed, an optimal TLR activation determines a proper innate immune response, while excessive TLR signal transduction and expression may promote an inflammatory response that causes damages to the host $[46,47]$. Here, we confirm that 
HRV is frequently found in the respiratory samples from CF patients of any age group. Moreover, we found that HRV detection was associated with the occurrence of pulmonary exacerbations in $18 \%$ of CF patients analyzed. In agreement, a potential role of HRV in CF exacerbation has been already reported $[19,38,48]$, highlighting the importance of HRV in managing the outcome of CF.

HRV load did not vary according to patients age but, of note, the results presented here are the first, to our knowledge, to indicate how HRV infection may affect the expression of TLR in CF patients. Among the TLR analysed, TLR2 and TLR4 are highly expressed in the respiratory tract of CF patients and, most importantly, their expression increased upon HRV infection. Interestingly, of all the TLRs, both TLR2 and TLR4, have emerged as the principal receptor responsible for orchestrating changes in inflammatory status in airway epithelial cells and several respiratory diseases including CF [14, 49, 50]. Indeed, our results are in part consistent with the observations that TLR2 and TLR4 expression and function are relevant in CF patients [51, 52, 53]. Moreover, we suggest that, together with well-established bacteria (e.g. S. aureus and P. aeruginosa), HRV can also participate in modulating the levels of TLRs in CF. Indeed, enhanced levels of TLR2 and TLR4 correlated with elevated amount of HRV viral load. In support of our observations, TLR2 has been shown to be important during HRV infection because it can recognize the viral protein 4 (VP4) of the capsid and it is also required and sufficient for HRV induced proinflammatory responses in vitro and in vivo [20]. HRV interaction with TLR2 can be also used to overcome the IFN response mediated by the stimulation of other TLRs. Indeed, it has been shown that HRV interaction with TLR2 causes ILRassociated kinase-1 (IRAK-1) depletion in both airway epithelial cells and macrophages, limiting single stranded RNA-induced IFN responses in dendritic cells by interfering with MyD88-dependent TLR7/9 signaling [54, 55, 56]. Unlike other respiratory viruses [57, 58], HRV does not activate TLR4 by a specific viral protein, but it might induce TLR4 activation by host DAMPs, such as high-mobility group box 1 protein (HMGB1) and oxidized phospholipids, which accumulate in response to viral infection $[59,60]$. The latter findings might explain why HRV infection promotes an increase of TLR4. However, John et al. $[9,61]$ have reported a reduced surface TLR4 expression in CF bronchial 
epithelial highlighting the complexity of the analyzed phenomenon. Moreover, levels of TLR8, known to be activated by viral or bacterial ssRNA and endogenous RNAs [62, 63], were slightly increased in HRV positive individuals and correlated also to HRV viral load. In this regard, it could be hypothesized that uridines sequences, which are abundant in HRV-RNA genome, might have immunostimulatory potential on TLR8 [64]. Of note, although expression of TLR2, TLR4 and TLR8 were higher in HRV A, B and C species positive patients as compared to HRV negative patients, HRV species were not associated to a type specific increase of any TLR analyzed.

Hence, our findings support the idea that an HRV infection may affect the airway microbial environment through the increased expression of specific TLRs, further promoting the intrinsic dysregulated inflammatory response observed in CF individuals. In agreement, many studies have reported higher levels of inflammatory mediators, mostly IL-8 and IL-6, produced by CF epithelium following HRV infection [51, 65]. However contradictory observations have been also been reported probably due in part to the different patients' age, disease severity, HRV species, HRV viral load, and length of infection [66].

Since the airways of individuals with CF are abundantly colonized by $S$. aureus and $P$. aeruginosa, the expression of TLRs was further examined dividing the CF patients according to the presence of S. aureus, $P$. aeruginosa or co-colonization by both bacteria. Results confirmed that expression of TLRs are increased in HRV positive patients according to their microbiological status but some important findings were observed. Notably, the difference in TLR2 and TLR4 levels among HRV positive and negative patients were more pronounced in those with $P$. aeruginosa colonization. Interestingly, HRV increased also the expression of TLR8 and TLR9 in addition to that of TLR2 and TLR4 when there was a co-colonization between $S$. aureus and $P$. aeruginosa, suggesting an additive/synergistic effects of all these pathogens on innate immune response which could be responsible of the worse clinical conditions. In this context it has been shown that bacterial-viral coexposure synergistically increases innate immune responses compared with individual bacterial 
presence $[67,68,69]$. Moreover, a significantly higher viral load of $P$. aeruginosa was observed during respiratory-virus associated exacerbations [43].

A major limitation of this study was that the amount of different cell type was not evaluated (e.g. epithelial and polymorphonuclear cells) in the respiratory samples collected from CF patients. Although all sputum samples were validated by the Bartlett's criteria, the limited quantities of oropharyngeal aspirate samples collected during microbiological diagnostic routine did not allow to perform any other additional test over than the molecular analysis described. Then, it remains unclear whether the TLR changes observed in HRV positive patients might be a representation of different cell populations rather than any difference in gene expression per se. Additional experiments are required with other techniques (e.g. flow cytometry) to ascertain which cell type within the respiratory samples is really responsible of the different expression levels of TLR in CF patients. A second potential limitation was related to the difficulty to categorize the positivity of respiratory samples to S. aureus as infection or colonization in our CF patients [70]. Since no consensus criteria for S. aureus are available and given that dissection of $S$. aureus infection from colonization continues to be debate in CF patients, we have categorized our CF patients only according to the duration of S. aureus positivity in the respiratory samples. Moreover, it might suggest to carefully evaluate if small colony variants $(\mathrm{SCVs})$ were detected in our respiratory samples, given they are implicated in chronic infections and are usually associated with a significantly worse respiratory outcome [71].

\section{Conclusion}

In conclusion our results indicated that the expression level of TLRs, in particular TLR2 and TLR4, increased in the respiratory tract of CF patients in the presence of an HRV infection and varied according to the microbiological status. Although the reasons leading to an unbalanced inflammatory response in HRV infections are not well understood and are most likely multifactorial in $\mathrm{CF}$, our results pointed out that the presence in the respiratory tract of multiple bacterial and viral potential TLR agonists represents a milieu causing a chronic activation of specific TLRs. Hence, the interplay 
between different microorganisms, virus and bacteria, may play a key role in the prognosis of $\mathrm{CF}$. Additional prospective studies with larger patient cohorts are needed to gain a more definitive understanding of the effects of virus/bacteria co-colonization on the overall innate immune response with the final aim to design a tailored immune-therapy to reduce over-inflammation in CF patients.

\section{Funding}

This work was supported by a grant to A.G. (Antonelli Guido) from Fondazione Ricerca Fibrosi Cistica-Onlus (FFC\#14/2018) and from Sapienza University (Fondi Progetti di ricerca universitaria 2018). Funding sources had no involvement in study design; in the collection, analysis and interpretation of data; in the writing of this manuscript; and in the decision to submit the article for publication. 
Table 1. Demographic, clinical characteristics, microbiological status and human rhinovirus (HRV) infection of cystic fibrosis $(\mathrm{CF})$ patients $(\mathrm{n}=294)$ divided by three age groups (0-10 years, 11-24 years, $>25$ years).

\begin{tabular}{|c|c|c|c|}
\hline \multirow{2}{*}{ Items } & \multicolumn{3}{|c|}{ Patients grouped by age $(n=294) \triangle$} \\
\hline & $0-10(n=63)$ & $11-24(n=102)$ & $>25(n=129)$ \\
\hline Male/Female & $37 / 26$ & $51 / 51$ & $60 / 69$ \\
\hline$\Delta \mathrm{F} 508$ homozigotes & 26 & 37 & 49 \\
\hline$\Delta$ F508 heterozigotes & 20 & 33 & 41 \\
\hline Other mutations & 17 & 32 & 39 \\
\hline BMI, median & 15.99 & 20.12 & 21.72 \\
\hline \multirow[t]{3}{*}{ BMI, range } & $12.7-25.4$ & $13.3-26.4$ & $12.9-36.0$ \\
\hline & \multicolumn{3}{|c|}{ Samples grouped by age $(n=515) \triangle \diamond$} \\
\hline & $0-10$ years $(n=131)$ & $11-24(n=170)$ & $>25(n=214)$ \\
\hline Non pathogenic microbes $(\%)$ & $14(10.7 \%)$ & $12(7 \%)$ & $8(3.7 \%)$ \\
\hline $\begin{array}{l}\text { Staphylococcus aureus chronic colonization } \\
\qquad \%) \circ\end{array}$ & $59(45 \%)$ & $67(39.5 \%)$ & $38(17.7)$ \\
\hline Pseudomonas aeruginosa colonization (\%) & $7(5.3 \%)$ & $8(4.7 \%)$ & $84(39.3)$ \\
\hline Pseudomonas aeruginosa mucoid phenotype & $1(0.8 \%)$ & $3(1.8 \%)$ & $52(24.3 \%)$ \\
\hline Presence of $S$. aureus and P. aeruginosa (\%) & $51(39 \%)$ & $83(48.8 \%)$ & $84(39.3)$ \\
\hline Other Gram - bacteria colonization $০ ০ ০$ & $4(3.0 \%)$ & $17(10 \%)$ & $37(17.3 \%)$ \\
\hline HRV-RNA detection (\%) & 23/131 (17.55\%) & $33 / 170(19.41 \%)$ & $24 / 214(11.21 \%)$ \\
\hline $\begin{array}{l}\text { HRV-RNA viral load median }\left(\log _{10}\right. \\
\text { copies/mL)* }\end{array}$ & 3.77 & 3.38 & 3.74 \\
\hline $\begin{array}{l}\text { HRV-RNA viral load range }\left(\log _{10}\right. \\
\text { copies } / \mathrm{mL}) * *\end{array}$ & $2.29-5.43$ & $1.66-5.79$ & $2.4-5.75$ \\
\hline
\end{tabular}

\footnotetext{
$\triangle$ Demographic, genetic and BMI data were comparable among the 3 age groups (p $>0.05$ by Chi-Squared test). $\triangle \triangle$ Almost patients were routinely seen in the hospital every 3 months * Difference for HRV-RNA detection in the age groups ( $p>0.05$ by Chi-Squared test). ${ }^{* *}$ HRV-RNA levels between the age groups: $\mathrm{p}>0.05$ by Kruskal-Wallis test. $\circ \geq 3$ consecutive positivity to S.aureus over at least 12 months $\circ \circ P$. aeuriginosa persistent colonization was stated according to the European consensus criteria [29]. 000 S. maltophilia, A. xylosoxidans and B. cepacia cplx colonization.
} 
Table 2. Levels of toll like receptors (TLRs) in rhinovirus (HRV) A-C positive and negative patients with cystic fibrosis.

\begin{tabular}{ccccc}
\hline & HRV A & HRV B & HRV C & HRV- \\
Items & $\mathrm{n}=24$ & $\mathrm{n}=12$ & $\mathrm{n}=19$ & $\mathrm{n}=55$ \\
\hline TLR2 median & $5.58^{*}$ & $5.46^{*}$ & $5.61^{*}$ & 1.00 \\
$($ range $)$ & $(0.03-30.69)$ & $(1.29-25.45)$ & $(0.32-27.09)$ & $(0.01-30.90)$ \\
TLR4 median & $5.42^{*}$ & $5.56^{*}$ & $5.69 *$ & 0.78 \\
$\begin{array}{c}\text { (range) } \\
\text { TLR8 median }\end{array}$ & $(1.61-30.27)$ & $(2.58-32)$ & $(1.45-20.53)$ & $(0.16-26.53)$ \\
$($ range $)$ & $(0.05-9.30)$ & $(0.22-3.91)$ & $(0.27-3.41)$ & $(0.01-11.14)$ \\
TLR3 median & 0.78 & 0.78 & 0.78 & 0.48 \\
$($ range $)$ & $(0.35-2.84)$ & $(0.25-1.08)$ & $(0.18-1.87)$ & $(0.00-9.06)$ \\
TLR9 median & 0.45 & 0.49 & 0.44 & 0.51 \\
$($ range $)$ & $(0.01-3.65)$ & $(0.04-0.53)$ & $(0.03-1.61)$ & $(0.00-6.49)$ \\
\hline
\end{tabular}

*Differences in TLR expression between HRV A-C positive and negative (HRV-) samples: $p<0.05$ by MannWhitney test. 
Table 3. Relationships between toll like receptors (TLRs) expression and patients' age, viral load and FEV1 in cystic fibrosis patients with or without human rhinovisus (HRV) infection.

\begin{tabular}{|c|c|c|c|c|c|c|}
\hline \multicolumn{2}{|c|}{ Correlations } & TLR2 & TLR4 & TLR8 & TLR3 & TLR9 \\
\hline \multirow{6}{*}{$\mathrm{HRV}+$} & \multirow{2}{*}{ Age } & $r=-0.09$ & $r=-0.07$ & $r=-0.18$ & $\mathrm{r}=0.03$ & $r=-0.17$ \\
\hline & & $p=0.52$ & $\mathrm{p}=0.59$ & $\mathrm{p}=0.19$ & $p=0.81$ & $\mathrm{p}=0.22$ \\
\hline & \multirow{2}{*}{ Viral load } & $r=0.39$ & $\mathbf{r}=\mathbf{0 . 2 9}$ & $r=0.42$ & $r=0.25$ & $r=0.08$ \\
\hline & & $p=0.003$ & $p=0.03$ & $p=0.001$ & $p=0.06$ & $\mathrm{p}=0.59$ \\
\hline & \multirow{2}{*}{ FEV1 } & $r=0.08$ & $r=0.03$ & $r=0.09$ & $r=-0.07$ & $r=-0.28$ \\
\hline & & $p=0.72$ & $\mathrm{p}=0.89$ & $p=0.67$ & $\mathrm{p}=0.74$ & $\mathrm{p}=0.19$ \\
\hline \multirow{4}{*}{ HRV- } & \multirow{2}{*}{ Age } & $r=-0.08$ & $r=-0.15$ & $r=-0.04$ & $r=0.05$ & $r=-0.28$ \\
\hline & & $\mathrm{p}=0.57$ & $\mathrm{p}=0.29$ & $\mathrm{p}=0.79$ & $\mathrm{p}=0.74$ & $\mathrm{p}=0.05$ \\
\hline & \multirow{2}{*}{ FEV1 } & $r=-0.06$ & $\mathrm{r}=0.13$ & $\mathrm{r}=0.12$ & $r=0.07$ & $\mathrm{r}=0.04$ \\
\hline & & $\mathrm{p}=0.71$ & $\mathrm{p}=0.39$ & $p=0.43$ & $p=0.64$ & $p=0.77$ \\
\hline
\end{tabular}

Spearman's rho coefficient (r) was used to assess these correlations. Significant correlations were highlighted in bold $(\mathrm{p}<0.05)$. 


\section{References}

1. Sadikot, R.T., Blackwell, T.S., Christman, J.W., Prince, A.S. Pathogen-host interactions in Pseudomonas aeruginosa pneumonia. Am J Respir Crit Care Med 2005; 171(11): 1209-1223 https://doi.org/10.1164/rccm.200408-1044SO

2. Muir, A., Soong, G., Sokol, S., Reddy, B., Gomez, M.I., et al. Toll-like receptors in normal and cystic fibrosis airway epithelial cells. Am J Respir Cell Mol Biol 2004; 30: 777-83 https://doi.org/10.1165/rcmb.2003-03290C

3. Ratner, A.J., Bryan, R., Weber, A., Nguyen, S., Barnes, D., et al. Cystic fibrosis pathogens activate $\mathrm{Ca} 2+-$ dependent mitogen-activated protein kinase signaling pathways in airway epithelial cells. J Biol Chem 2001; 276: 19267-19275 10.1074/j-bc.M007703200

4. Greene, C.M., Carroll, T.P., Smith, S.G.J., Taggart, C.C., Devaney, J., et al. TLR-induced inflammation in cystic fibrosis and non-cystic fibrosis airway epithelial cells. J Immunol 2005; 174(3): 1638-1646 https://doi.org/10.4049/jimmunol.174.3.1638

5. Zarember, K.A., Godowski, P.J. Tissue expression of human Toll-like receptors and differential regulation of Toll-like receptor mRNAs in leukocytes in response to microbes, their products, and cytokines. J Immunol 2002; 168(2): 554-56 https://doi.org/10.4049/jimmunol.16-

\section{$\underline{8.2 .554}$}

6. Becker, M.N., Diamond, G., Verghese, M.W., Randell, S.H. CD-14-dependent lipopolysaccharide induced beta-defensin-2 expression in human tracheobronchial epithelium. J Biol Chem 2000; 275: 29731-29736 10.1074/jbc.M000184200

7. Krivan, H.C., Roberts, D.D., Ginsburg, V. Many pulmonary pathogenic bacteria bind specifically to the carbohydrate sequence GalNAc beta 1-4Gal found in some glycolipids. Proc Natl Acad Sci USA 1988; 85(16): 6157-6161 https://doi.org/10.1073/pnas.85.16.6157

8. Hauber, H.P., Tulic, M.K., Tsicopoulos, A., Wallaert, B., Olivenstein, R., et al. Toll-like receptors 4 and 2 expression in the bronchial mucosa of patients with cystic fibrosis. Can Respir J 2005; 12: 13-8 http://dx.doi.org/10.1155/2005/648984 
9. John, G., Yildirim, A.O., Rubin, B.K., Gruenert, D.C., Henke, M.O. TLR-4-mediated innate immunity is reduced in cystic fibrosis airway cells. Am J Respir Cell Mol Biol 2010; 42(4): 424431 https://doi.org/10.1165/rcmb.2008-04080C

10. Kelly, C., Canning, P., Buchanan, P.J., Williams, M.T., Brown, V., et al. Toll-like receptor 4 is not targeted to the lysosome in cystic fibrosis airway epithelial cells. Am J Physiol Lung Cell Mol Physiol 2013; 304: 371-382 https://doi.-org/10.1152/ajplung.00372.2011

11. Cantin, A.M., Hartl, D., Konstan, M.W., Chmiel, J.F. Inflammation in cystic fibrosis lung disease: pathogenesis and therapy. J Cystic Fibrosis 2015; 14(4): 419-430 https://doi.org/10.1152/aj-plung.00372.2011

12. Beaudoin, T., LaFayette, S., Nguyen, D., Rousseau, S. Mucoid Pseudomonas aeruginosa caused by mucA mutations result in activation of TLR2 in addition to TLR5 in airway epithelial cells. Biochem Biophys Res Commun 2012; 428(1): 150-154 https://doi.org/10.1016/j.bbrc.20$\underline{12.10 .030}$

13. Etherington, C., Naseer, R., Conway, S.P., Whitaker, P., Denton, M., et al. The role of respiratory viruses in adult patients with cystic fibrosis receiving intravenous antibiotics for a pulmonary exacerbation. J Cyst Fibros 2014; 13(1): 49-55 https://doi.org/10.1016/j.jcf.2013. $\underline{06.004}$

14. Armstrong, D., Grimwood, K., Carlin, J.B., Carzino, R., Hull, L., et al. Severe viral respiratory infections in infants with cystic fibrosis. Pediatr Pulmonol 1998; 26(6): 371-9 https://doi.org/10.1002/(SICI)1099-0496(199812)26:6<371::AID-PPUL1>3.0.CO;2-N

15. Kusel, M.M., de Klerk, N.H., Holt, P.G., Kebadze, T., Johnston, S.L., et al. Role of respiratory viruses in acute upper and lower respiratory tract illness in the first year of life: a birth cohort study. Pediatr Infect Dis J 2006; 25(8): 680-686 10.1097/01.inf.0000226912.88900.a3

16. Stelzer-Braid, S., Liu, N., Doumit, M., D'Cunha, R., Belessis, Y., et al. Association of rhinovirus with exacerbations in young children affected by cystic fibrosis: preliminary data. J Med Virol 2017; 89(8): 1494-1497 https://doi.org/10.1002/jmv.24794 
17. Kieninger, E., Singer, F., Tapparel, C., Alves, M.P., Latzin, P., et al. High rhinovirus burden in lower airways of children with cystic fibrosis. Chest 2013; 143(3): 782-90 https://doi.org/10.1378/chest.12-0954

18. Flight, W.G., Bright-Thomas, R.J., Tilston, P., Mutton, K.J., Guiver, M., et al. Incidence and clinical impact of respiratory viruses in adults with cystic fibrosis. Thorax 2014; 69: 247-253 http://dx.doi.org/10.1136/thoraxjnl-2013-204000

19. Goffard, A., Lambert, V., Salleron, J., Herwegh, S., Engelmann, I., et al. Virus and cystic fibrosis: rhinoviruses are associated with exacerbations in adult patients. J Clin Virol 2014; 60(2): 147-153 https://doi.-org/10.1016/j.jcv.2014.02.005

20. Bentley, J.K., Han, M., Jaipalli, S., Hinde, J.L., Lei, J., et al. Myristoylated rhinovirus VP4 protein activates TLR2-dependent proinflammatory gene expression. Am J Physiol Lung Cell Mol Physiol 2019; 317(1): 57-70 https://doi.org/10.1152/ajplung.00365.2018

21. Baum, A., García-Sastre, A. Induction of type I interferon by RNA viruses: cellular receptors and their substrates. Amino Acids 2010; 38(5): 1283-1299 http://dx.doi.org/10.1007/s00726-011$\underline{0844-\mathrm{Z}}$

22. Han, M., Chung, Y., Young Hong, J., Rajput, C., Lei, et al. Toll-like receptor 2-expressing macrophages are required and sufficient for rhinovirus-induced airway inflammation. J Allergy Clin Immunol 2016; 138(6): 1619-1630 https://doi.org/10.-1016/j.jaci.2016.01.037

23. Melvin, T.A., Lane, A.P., Nguyen, M.T., Lin S.Y. Sinonasal epithelial cell expression of Tolllike receptor 9 is elevated in cystic fibrosis-associated chronic rhinosinusitis. Am $\mathrm{J}$ Rhinol Allergy 2013; 27(1): 30-3 https://doi.org/10.2500/ajra.2013.27.3834

24. Maciejewski, B.A., Jamieson, K.C., Arnason, J.W., Kooi, C., Wiehler, S., et al. Rhinovirusbacteria coexposure synergistically induces CCL20 production from human bronchial epithelial cells. Am J Physiol Lung Cell Mol Physiol 2017; 312(5): 731-740 https://doi.org/10.1152/ajplung.00362.2016 
25. Chaudhuri, N., Dower, S.K., Whyte, M.K., Sabroe, I. Toll-like receptors and chronic lung disease. Clin Sci (Lond) 2005; 109(2): 125-33 https://doi.org/10.1042/CS20050044

26. Greene, C.M., Branagan, P., McElvaney, N.G. Toll-like receptors as therapeutic targets in cystic fibrosis. Expert Opin Ther Tar 2008; 12(12): 1481-1495 https://doi.org/10.1517/1472$\underline{8220802515293}$

27. Triantafilou, K., Vakakis, E., Richer, E.A.J., Evans, G.L., Villiers, J.P., et al. Human rhinovirus recognition in non-immune cells is mediated by Toll-like receptors and MDA-5, which trigger a synergetic pro-inflammatory immune response. Virulence 2008; 2(1): 22-29 https://doi.org/10.4161/viru.2.1.13807

28. Bartlett, J.G., Breiman, R.F., Mandell, L.A., File, T.M. Community-acquired pneumonia in adults:guidelines for management. Clin Infect Dis 1998; 26(4): 811-838 https://doi.org/10.1086/ 513953 PMid:9564457.

29. DoÈring, G., Conway, S.P., Heijerman, H.G.M., Hodson, M.E., Hùiby, N., et al. for the Consensus Committee. Antibiotic therapy against Pseudomonas aeruginosa in cystic fibrosis: a European consensus. Eur Respir J 2000; 16(4): 749-767 https://doi.org/10.1034/j.1399$\underline{3003.2000 .16 \mathrm{~d} 30 . \mathrm{x}}$

30. Fritz, S.A., Krauss M.J., Epplin E.K., Burnham, C.A., Garbutt, J., et al. The Natural History of Contemporary Staphylococcus aureus Nasal Colonization in Community Children. Pediatr Infect Dis J 2011; 30(4): 349-351 https://doi.org/10. 1097/INF.0b013e3181fe075e

31. Pierangeli, A., Gentile, M., Di Marco, P., Pagnotti, P., Scagnolari, C., et al. Detection and typing by molecular techniques of respiratory viruses in children hospitalized for acute respiratory infection in Rome, Italy. J Med Virol 2007; 79(4): 463-8 https://doi.org/10.1002/jmv.20832

32. Pierangeli, A., Statzu, M., Nenna, R., Santinelli, L., Petrarca, L., et al. Interferon lambda receptor 1 (IFNL1R) transcript is highly expressed in rhinovirus bronchiolitis and correlates with disease severity. J Clin Vir 2018; 102: 101-109 https://doi.org/10.10-16/j.jcv.2018.03.003 
33. Kiang, D., Kalra, I., Yagi, S., Louie, J.K., Boushey, H., et al. Assay for 5' noncoding region analysis of all human rhinovirus prototype strains. J Clin Microbiol 2008; 46(11): 3736-3745 https://doi.org/10.1128/JCM.00674-08

34. Selvaggi, C., Pierangeli, A., Fabiani, M., Spano, M., Nicolai, A., et al. Interferon lambda 1e3 expression in infantshospitalized for RSV or HRV associated bronchiolitis. J Inf 2014; 68(5): 467-477 https://doi.org/10.-1016/j.jinf.2013.12.010

35. Tapparel, C., Cordey, S., Van Belle, S., Turin, L., Lee, W.M., et al. New molecular detection tools adapted to emerging rhinoviruses and enteroviruses. J Clin Microbiol 2009; 47(6): 17421749 http://doi.org/10.1128/JCM.02339-08

36. Statzu, M., Santinelli, L., Viscido, A., Pinacchio, C., Ceccarelli, G., et al. Increased SAMDH1 transcript expression correlates with interferon-related genes in HIV-1-infected patients. Med Microbiol Immunol 2019; 208(3): 679-691 https://doi.org/10.1007/s00430-018-0574-X

37. Flight, W.G., Bright-Thomas, R.J., Tilston, P., Mutton, K., Guiver M., et al. Chronic rhinovirus infection in an adult with cystic fibrosis. J Clin Microbiol 2013; 51(11): 3893-3896 http://doi.org/10.1128/JCM.01604-13

38. De Almeida, M.B., Zerbinati, R.M., Tateno, A.F., Oliveira, C., et al. Rhinovirus C and respiratory exacerbations in children with cystic fibrosis. Emerg Infect Dis 2010; 16(6): 996-9 http://doi. org/10.3201/eid1606.100063

39. Nixon, G.M., Armstrong, D.S., Carzino, R., Carlin, J.B., Olinsky, A., et al. Early airway infection, inflammation, and lung function in cystic fibrosis. Arch Dis Child 2002; 87(4): 306-311 http://dx.doi.org/10.1136/adc.87.4.306

40. Muhlebach, M.S., Stewart, P.W., Leigh, M.W., Noah, T.L. Quantification of inflammatory responses to bacteria in young cistic fibrosis and control patients. Am J Respir Crit Care Med 1999; 160: 186-191 https://doi.org/10.1164/ajrccm.160.1.9808096 
41. Khan, T.Z., Wagner, J.S., Bost, T., Martinez, J., Accurso, F.J., et al.. Early pulmonary inflammation in infants with cystic fibrosis. Am J Respir Crit Care Med 1995; 151(4): 1075-1082 https://doi.org/10.1164/ajrccm.151.4.7697234

42. Burns, J.L., Emerson, J., Kuypers, J., Campbell, A., Gibson, R.L., et al. Respiratory viruses in children with cystic fibrosis: viral detection and clinical findings. Influenza Other Respir Viruses 2011; 6(3): 218-223 https://doi.org/10.1111/j.1750-2659.2011.00292.x

43. Wark, P.B., Tooze, M., Cheese, L., Whitehead, B., Gibson, P.G., et al. Viral infections trigger exacerbations of cystic fibrosis in adults and children. Eur Resp J 2012; 40: 510-512 $\underline{10.1183 / 09031936.00202311}$

44. Dijkema, J.S., van Ewijk, B.E., Wilbrink, B., Wolfs, T.F., Kimpen, J.L., et al. Frequency and Duration of Rhinovirus Infections in Children with Cystic Fibrosis and Healthy Controls: A Longitudinal Cohort Study. Pediatr Infect Dis J 2016; 35(4): $379-83 \quad \underline{10.1-}$ 097/INF.0000000000001014

45. Kiedrowski, M.R., Bomberger, J.M. Viral-Bacterial Co-infections in the Cystic Fibrosis Respiratory Tract. Front Immunol 2018; 20(9): 3067 https://doi.org/10.-3389/fimmu. $\underline{2018.03067}$

46. Lafferty, E.I., Qureshi, S.T., Schnare, M. The role of toll-like receptors in acute and chronic lung inflammation. J Inflamm 2010; 7: 57 https://doi.org/10.1186/1476-9255-7-57

47. Cohen-Cymberknoh, M., Kerem, E., Ferkol, T., Elizur, A. Airway inflammation in cystic fibrosis: molecular mechanisms and clinical implications. Thorax 2013; 68(12): 1157-1162 http://dx.doi.org/10.1136/thoraxjnl-2013-203204

48. Shah, A., Connelly, M., Whitaker, P., McIntyre, C., Etherington, C., et al. Pathogenicity of individual rhinovirus species during exacerbations of cystic fibrosis. Eur Respir J 2015; 45(6): 17481751 https://doi.org/10.1183/09031936.00229114 
49. Dong, Z., Xiong, L., Zhang, W., Gibson, P.G., Wang, T., et al. Holding the Inflammatory System in Check: TLRs and Their Targeted Therapy in Asthma. Mediat Inflamm 2016; 2016: 2180417 http://dx.doi.org/10.1155/2016/2180417

50. Adamo, R., Sokol, S., Soong, G., Gomez, M.I., Prince, A. Pseudomonas aeruginosa flagella activate airway epithelial cells through asialoGM1 and Toll-like receptor 2 as well as Toll-like receptor 5. Am J Respir Cell Mol Biol 2004; 30(5): 627-634 https://doi.org/10.1165/rcmb.2003$\underline{02600 C}$

51. Shuto, T., Furuta, T., Oba, M., Xu, H., Li, J.D., et al. Promoter hypomethylation of Toll-like receptor-2 gene is associated with increased proinflammatory response toward bacterial peptidoglycan in cystic fibrosis bronchial epithelial cells. Faseb J 2006; 20(6): 782-4 https://doi.org/10.1096/fj.05-4934fje

52. Furuta, T., Shuto, T., Shimasaki, S., Ohiro, Y., Suico, M.A., et al. DNA demethylationdependent enhancement of toll-like receptor-2 gene expression in cystic fibrosis epithelial cells involves SP1-activated transcription. BMC Mol Biol 2008; 9:39 https://doi.-org/10.1186/14712199-9-39

53. Koller, B., Kappler, M., Latzin, P., Gaggar, A., Schreiner, M., et al. TLR Expression on Neutrophils at the Pulmonary Site of Infection: TLR1/TLR2-Mediated Up-Regulation of TLR5 Expression in Cystic Fibrosis Lung Disease. J Immunol 2008; 181(4): 2753-2763 https://doi.org/10.4049/jimmunol.181.4.2753

54. Schneider, D., Ganesan, S., Comstock, A.T., Meldrum, C.A., Mahidhara, R., et al. Increased cytokine response of rhinovirus-infected airway epithelial cells in chronic obstructive pulmonary disease. Am J Respir Crit Care Med 2010;182(3): 332-340 https://doi.org/10.1164/rccm.200911-16730C

55. Unger, B.L, Faris, A.N., Ganesan, S., Comstock, A.T., Hershenson, M.B., et al. Rhinovirus Attenuates Non-typeable Hemophilus influenzae-stimulated IL-8 Responses via TLR2- 
dependent Degradation of IRAK-1. PLoS Pathog 2012; 8(10): e1002969 https://doi.org/10.$\underline{1371 / \text { journal.ppat.1002969 }}$

56. Liu, Y.C., Simmons, D.P., Li, X., Abbott, D.E., Boom, W.H., et al. TLR2 signaling depletes IRAK1 and inhibits induction of type I IFN by TLR7/9. J Immunol 2012; 188(3): 10191026 https://doi.org/10.4049/jimmunol.1102181

57. Marr, N., Turvey, S.E. Role of human TLR4 in respiratory syncytial virus-induced NFkappaB activation, viral entry and replication. Innate Immun 2012; 18(6): 856-65 https://doi.$\underline{\operatorname{org} / 10.1177 / 1753425912444479}$

58. Olejnik, J., Hume, A.J., Mühlberger, E. Toll-like receptor 4 in acute viral infection: Too much of a good thing. PLoS Pathog 2018; 14(12): e1007390 https://doi.org/10.1371/journal.ppat.1007390 59. Schlegel, C.R., Ivanciuc, T., Garofalo, R.P., Palkowetz, K.H., Fuller, K.A., et al. Release of High-Mobility Group Box-1 (HMGB1) in the Airways of Children with Viral Lower Respiratory Tract Infections. J Allergy Clin Immunol 2015; 135(2): Supplement AB230 https://doi.org/10.1016/j.jaci.2014.12.1686

60. Patel, M.C., Shirley, K.A., Boukhalova, M.S., Stefanie, N., Vogel, S.N., et al. Serum HighMobility-Group Box 1 as a Biomarker and a Therapeutic Target during Respiratory Virus Infections. MBio 2018; 9(2): e00246-18 10.1128/mBio.00246-18

61. John, G., Chillappagari, S., Rubin, B.K., Gruenert, D.C., Henke, M.O. Reduced surface toll-like receptor-4 expression and absent interferon- $\gamma$-inducible protein-10 induction in cystic fibrosis airway cells. Exp Lung Res 2011; 37(6): 319-326 https://doi.org/10.3109/019021 48.2011.569968 62. Hornung, V., Guenthner-Biller, M., Bourquin, C., Ablasser, A., Schlee, M., et al. Sequencespecific potent induction of IFN-a by short interfering RNA in plasmacytoid dendritic cells through TLR7. Nat Med 2005; 11: 263-270 https://doi.org/10.1038/nm1191

63. Barrat, F.J., Meeker, T., Gregorio, J., Chan J.H., Uematsu, S., et al. Nucleic acids of mammalian origin can act as endogenous ligands for Toll-like receptors and may promote systemic lupus erythematosus. J Exp Med 2005; 202(8): 1131-1139 10.1084/jem.20050914 
64. Tanji, H., Ohto, U., Shibata, T., Taoka, M., Yamauchi, Y., et al. Toll-like receptor 8 senses degradation products of single-stranded RNA. Nat Struc Mol Biol 2015; 22: 109-115 https://doi.org/10.1038/nsmb.2943

65. Firoved, A.M., Ornatowski, W., Deretic, V. Microarray analysis reveals induction of lipoprotein genes in mucoid Pseudomonas aeruginosa: implications for inflammation in cystic fibrosis. Infect Immun 2004; 72(9): 5012-5018 10.1128/IAI.72.9.5012-5018.2004

66. Ling, K.M., Garratt, L.W., Lassmann, T., Stick, S.M., Kicic, A., WAERP, AusREC, Australian Respiratory Early Surveillance Team for Cystic Fibrosis. Elucidating the Interaction of CF Airway Epithelial Cells and Rhinovirus: Using the Host-Pathogen Relationship to Identify Future Therapeutic Strategies. Front Pharmacol 2018; 9: 1270 https://doi.org/10.3389/fphar. 2018.01270 67. Hendricks, M.R., Lashua, L.P., Fischer, D.K., Flitter, B.A., Eichinger, K.M., et al. Respiratory syncytial virus infection enhances Pseudomonas aeruginosa biofilm growth through dysregulation of nutritional immunity. Proc Natl Acad Sci USA 2016; 113(6):1642-1647 $\underline{10.1073 / \text { pnas. } 1516979113}$

68. Kiedrowski, M.R., Gaston, J.R., Kocak, B.R., Coburn, S.L., Lee, S., et al. Staphylococcus aureus Biofilm Growth on Cystic Fibrosis Airway Epithelial Cells Is Enhanced during Respiratory Syncytial Virus Co-infection. mSphere 2018; 3: e00341-18 10.-1128/mSphere .00341-18

69. Chattoraj, S.S., Ganesan, S., Jones, A.M., Helm, J.M., Comstock, A.T., et al. Rhinovirus infection liberates planktonic bacteria from biofilm and increases chemokine responses in cystic fibrosis airway epithelial cells, Thorax 2011; 66(4): 333-339 http://dx.doi. $\underline{\operatorname{org} / 10.1136 / \text { thx.2010.151431 }}$

70. Hurley, M.N. Staphylococcus aureus in cystic fibrosis: problem bug or an innocent bystander? Breathe. 2018; 14(2): 87-90 https://doi.org/10.1183/20734735.014718

71. Loss, G., Martins Simões, P., Valour, F., Farrel Cortês, M., Gonzaga, L., et al. Staphylococcus aureus Small Colony Variants (SCVs): News From a Chronic Prosthetic Joint Infection Front Cell Infect Microbiol. 2019; 9: 363 http://doi.org/10.3389/fcimb.2019.00363 
Fig. 1 Distribution by patients' age groups (0-10 years, 11-25 years, >25 years) of human rhinovirus (HRV) positivity in the samples $(n=515)$ collected from cystic fibrosis patients $(n=309)$ according to the Staphylococcus aureus (SA) colonization, Pseudomonas aeruginosa (PA) colonization and cocolonization by $S$. aureus and $P$. aeruginosa. Number of HRV+ and HRV- according to the microbiological status ( $S$. aureus, P. aeruginosa and co-colonization by both bacteria) were comparable in each age group ( $p>0.05$ by Chi-Squared tests).

Fig. 2. Expression levels of genes encoding TLR2 (Panel A), TLR3 (Panel B), TLR4 (Panel C), TLR8 (Panel D) and TLR9 (Panel E) in cystic fibrosis (CF) patients with $(n=55)$ or without human rhinovirus (HRV) $(\mathrm{n}=55)$ infection, stratified according to the microbiological status: Staphylococcus aureus (SA), Pseudomonas aeruginosa (PA) and co-colonization by both bacteria $(\mathrm{SA}+\mathrm{PA}) .{ }^{*} \mathrm{p} \leq 0.05 * * \mathrm{p} \leq 0.01 * * * \mathrm{p} \leq 0.001 * * * * \mathrm{p} \leq 0.0001$. Levels of TLRs between HRV+ and HRV-patients were compared by Mann 